Rev. Bras. Saúde Prod. Anim., Salvador, v.15, n.3, p.613-625 jul./set., 2014 http://www.rbspa.ufba.br ISSN 15199940

\title{
Níveis de prebiótico na dieta sobre o desempenho e a qualidade de ovos de codornas japonesas
}

\section{Prebiotic levels in the diet on performance and egg quality of Japanese quail}

\author{
LEMOS, Marina Jorge de ${ }^{1 *}$; CALIXTO, Lígia Fátima Lima ${ }^{1}$; LIMA, Cristina Amorim \\ Ribeiro de ${ }^{1}$; REIS, Túlio Leite ${ }^{3}$; REGO, Ramon Souza ${ }^{1}$; NAK, So Yin ${ }^{1}$; AROUCHA, \\ Rômulo Jordão Neves ${ }^{4}$
}

\footnotetext{
${ }^{1}$ Universidade Federal Rural do Rio de Janeiro, Instituto de Zootecnia, Programa de Pós-Graduação em Zootecnia, Seropédica, Rio de Janeiro, Brasil.

${ }^{2}$ Universidade Federal Rural do Rio de Janeiro, Instituto de Zootecnia, Seropédica, Rio de Janeiro, Brasil.

*Endereço para correspondência: marijorgelemos@ hotmail.com
}

\section{RESUMO}

Objetivou-se avaliar os benefícios da adição da parede celular de Sacharomyces cerevisiae (PCSC) e seu melhor nível de inclusão na dieta sobre o desempenho e a qualidade dos ovos produzidos por codornas japonesas (Coturnix coturnix japonica) na fase de produção. Foram utilizadas 400 codornas japonesas distribuídas em um delineamento inteiramente casualizado, com cinco tratamentos e 10 repetições com 8 aves cada. Foram utilizadas cinco dietas com diferentes níveis de parede celular de $S$. cerevisiae $(0 \mathrm{~kg} / \mathrm{t} ; 0.5 \mathrm{~kg} / \mathrm{t} ; 1.0 \mathrm{~kg} / \mathrm{t} ; 1.5 \mathrm{~kg} / \mathrm{t}$; $2.0 \mathrm{~kg} / \mathrm{t}$ ). Para análise do desempenho das aves e da qualidade dos ovos, as variáveis avaliadas foram: o consumo de ração, a produção de ovos, o peso médio dos ovos, a massa de ovos, a conversão alimentar por massa, a conversão alimentar por dúzia de ovos produzidos, a viabilidade, a percentagem dos constituintes do ovo (gema, albúmen e casca) e a espessura de casca. O peso dos ovos, a massa de ovos, a viabilidade, a percentagem da gema e a percentagem do albúmen não foram influenciadas pela inclusão de parede celular de $S$. cerevisiae na dieta das codornas japonesas. A inclusão de níveis crescentes de parede celular de $S$. cerevisiae até o nível de $1,5 \mathrm{~kg} / \mathrm{t}$ na dieta melhorou a produção, a conversão alimentar por dúzia, a conversão alimentar por massa e a qualidade da casca de ovos produzidos por codornas japonesas durante a fase de produção.

Palavras-chave: Coturnix coturnix japônica. Espessura da casca. Parede celular de Sacharomyces cerevisiae.

\section{SUMMARY}

Aimed to evaluate the benefits of adding the cell wall of Saccharomyces cerevisiae (CWSC) and its best level in the diet on the performance and quality of eggs produced by Japanese quail (Coturnix coturnix japonica), during the production phase. 400 Japanese quails, were distributed in a complete random design, with five treatments and 10 replicates with 8 birds each. It was used five diets with different levels of cell wall of $S$. cerevisiae $(0 \mathrm{~kg} / \mathrm{t} ; 0.5 \mathrm{~kg} / \mathrm{t}$; $1.0 \mathrm{~kg} / \mathrm{t} ; 1.5 \mathrm{~kg} / \mathrm{t} ; 2.0 \mathrm{~kg} / \mathrm{t})$. To analyze the performance of birds and egg quality, the variables evaluated were: feed intake, egg production, egg weight, egg mass, feed conversion per dozen of eggs produced, feed conversion per mass of eggs produced, viability, percentage of the yolk, percentage of the albumen, percentage of the shell and shell thickness. Egg weight, percentage of yolk and percentage of albumen were not influenced by the inclusion of cell wall of $S$. cerevisiae in the diet of Japanese quails. The increasing levels of cell wall of $S$. cerevisiae to the level of $1.5 \mathrm{~kg} / \mathrm{t}$ in the diet improved production, feed conversion per dozen, feed conversion per mass and shell quality of eggs produced by Japanese quail during the production phase.

Keywords: Cell wall of Saccharomyces cerevisiae. Coturnix coturnix japonica. Shell thickness. 
INTRODUÇÃO

A coturnicultura é um setor da avicultura brasileira que está em constante crescimento. Fatores motivantes como rápido crescimento, maturidade sexual precoce, alta produtividade, baixo investimento e rápido retorno financeiro, têm contribuído para expansão da coturnicultura no cenário da avicultura brasileira. (PASTORE et al., 2012)

A produção avícola com alta produtividade a baixo custo é quase impossível sem a utilização de aditivos alimentares (OTUTUMI et al., 2008), dessa forma, buscam-se estratégias alternativas no intuito de melhorar o desempenho produtivo, por exemplo, a utilização de prebióticos.

Prebióticos são aditivos zootécnicos cuja principal forma de ação é a estimulação do crescimento e/ou ativação do metabolismo de algum grupo de bactérias benéficas do trato gastrintestinal. (SILVA \& NORNBERG, 2003) Os efeitos resultantes de seu uso são evidenciados pelo crescimento das populações microbianas benéficas, melhoria das condições luminais (IMMERSEEL et al., 2004) e das características anatômicas do trato gastrintestinal, promovendo o aumento da superfície de absorção da mucosa intestinal, podendo provocar melhoria no desempenho animal. (COSTA et al., 2008; IBRAHIM, 2011; OLIVEIRA et al., 2009; SIMS et al., 2004)

Além do desempenho, estudos relatam que o uso de prebiótico pode melhorar a qualidade dos ovos, principalmente a casca, pois quando o prebiótico alcança o intestino grosso ele é fermentado e convertido em ácido graxo de cadeia curta, diminuindo o $\mathrm{pH}$ luminal, solubilizando o cálcio e favorecendo sua absorção, consequentemente melhorando a qualidade da casca. (KRUGER et al.,
2003; OLIVEIRA et al., 2009; YOUSEFI \& KARKOODI, 2007)

Um prebiótico que tem sido muito estudado e utilizado é a parede celular de Saccharomyces cerevisiae, produto da extração do conteúdo celular da levedura e rica num oligossacarídeo a base de alfa-manose e beta-glucose (KOGAN \& KOCHER, 2007), o mananoligossacarídeo (MOS).

Diversas pesquisas sobre o uso de prebióticos foram desenvolvidas com frangos e galinhas poedeiras, no entanto, são escassos dados sobre a sua utilização em codornas, e a extrapolação dos resultados obtidos com outras categorias de aves para essa espécie pode não resultar em índices zootécnicos satisfatórios. Neste contexto, objetivou-se avaliar os benefícios da adição da parede celular de $S$. cerevisiae e seu melhor nível de inclusão na dieta sobre o desempenho e a qualidade dos ovos produzidos por codornas japonesas na fase de produção.

\section{MATERIAL E MÉTODOS}

$\mathrm{O}$ experimento foi realizado no galpão experimental do Setor de Avicultura da Universidade Federal Rural do Rio de Janeiro (UFRRJ), no período de junho a setembro de 2011, com uma duração de 112 dias divididos em cinco períodos de 21 dias cada, com sete dias de período de adaptação. Foram utilizadas 400 codornas japonesas (Coturnix coturnix japonica) com 42 dias de idade, criadas até 22 semanas de idade. As aves foram distribuídas em um delineamento inteiramente casualizado com 5 tratamentos e 10 repetições de 8 aves cada.

Os tratamentos adotados foram os seguintes: Controle - dieta referência (DR) sem inclusão de parede celular de S. cerevisiae; $\mathrm{PCSc} 0.5-\mathrm{DR}+0,5 \mathrm{~kg} / \mathrm{t}$ de parede celular de $S$. cerevisiae; 
Rev. Bras. Saúde Prod. Anim., Salvador, v.15, n.3, p.613-625 jul./set., 2014 http://www.rbspa.ufba.br ISSN 15199940

PCSc $1-\mathrm{DR}+1,0 \mathrm{~kg} / \mathrm{t}$ de parede celular de $S$. cerevisiae; PCSc1.5 - DR + $1,5 \mathrm{~kg} / \mathrm{t}$ de parede celular de $S$. cerevisiae; $\mathrm{PCSc} 2-\mathrm{DR}+2,0 \mathrm{~kg} / \mathrm{t}$ de parede celular de $S$. cerevisiae. As dietas foram formuladas (Tabela 1) de forma a atender as exigências mínimas nutricionais de codornas japonesas na fase de produção de acordo com Rostagno et al. (2011).
A escolha dos níveis de prebiótico testados foi baseada na recomendação do fabricante para aves $(1,0 \mathrm{~kg} / \mathrm{t}$ a $1,5 \mathrm{~kg} / \mathrm{t})$. Além dos níveis recomendados, foram fixados um nível abaixo e um nível acima $(0,5 \mathrm{~kg} / \mathrm{t}$ e $2,0 \mathrm{~kg} / \mathrm{t}$ ) para composição dos tratamentos.

Tabela 1. Composição percentual e calculada das rações experimentais para codornas japonesas em produção

\begin{tabular}{|c|c|c|c|c|c|}
\hline \multirow{2}{*}{ Ingredientes (\%) } & \multicolumn{5}{|c|}{ Tratamentos } \\
\hline & Controle & PCSc0.5 & PCSc1 & PCSc1.5 & PCSc2 \\
\hline Milho $(8,55 \%$ PB $)$ & 53,547 & 53,547 & 53,547 & 53,547 & 53,547 \\
\hline Farelo de Soja $(45,96 \%$ PB) & 34,60 & 34,60 & 34,60 & 34,60 & 34,60 \\
\hline Óleo de soja & 2,116 & 2,116 & 2,116 & 2,116 & 2,116 \\
\hline Sal comum & 0,333 & 0,333 & 0,333 & 0,333 & 0,333 \\
\hline Calcário calcítico & 7,110 & 7,110 & 7,110 & 7,110 & 7,110 \\
\hline Fosfato Bicálcico & 1,010 & 1,010 & 1,010 & 1,010 & 1,010 \\
\hline Mistura Vitamínica ${ }^{1}$ & 0,100 & 0,100 & 0,100 & 0,100 & 0,100 \\
\hline Mistura Mineral $^{2}$ & 0,400 & 0,400 & 0,400 & 0,400 & 0,400 \\
\hline DL-Metionina $(99 \%)$ & 0,347 & 0,347 & 0,347 & 0,347 & 0,347 \\
\hline L-Lisina HCL (78\%) & 0,149 & 0,149 & 0,149 & 0,149 & 0,149 \\
\hline Cloreto de colina & 0,035 & 0,035 & 0,035 & 0,035 & 0,035 \\
\hline Antioxidante BHT & 0,01 & 0,01 & 0,01 & 0,01 & 0,01 \\
\hline $\mathrm{PCSc}^{3}$ & 0,00 & 0,05 & 0,10 & 0,15 & 0,20 \\
\hline Caulim & 0,25 & 0,20 & 0,15 & 0,10 & 0,05 \\
\hline \multicolumn{6}{|c|}{ Composição nutricional calculada } \\
\hline Energia metabolizável (Mcal/kg) & 2,80 & 2,80 & 2,80 & 2,80 & 2,80 \\
\hline Proteína Bruta (PB\%) & 20,449 & 20,449 & 20,449 & 20,449 & 20,449 \\
\hline Cálcio $(\mathrm{Ca} \%)$ & 3,072 & 3,072 & 3,072 & 3,072 & 3,072 \\
\hline Fósforo disponível (P disp.\%) & 0,292 & 0,292 & 0,292 & 0,292 & 0,292 \\
\hline Cloro $(\%)$ & 0,243 & 0,243 & 0,243 & 0,243 & 0,243 \\
\hline Lisina Digestível (\%) & 1,110 & 1,110 & 1,110 & 1,110 & 1,110 \\
\hline Lisina Total $(\%)$ & 1,204 & 1,204 & 1,204 & 1,204 & 1,204 \\
\hline Metionina + Cistina digestível $(\%)$ & 0,901 & 0,901 & 0,901 & 0,901 & 0,901 \\
\hline Metonina + Cistina total (\%) & 0,976 & 0,976 & 0,976 & 0,976 & 0,976 \\
\hline Metionina digestível (\%) & 0,633 & 0,633 & 0,633 & 0,633 & 0,633 \\
\hline Metionina total (\%) & 0,665 & 0,665 & 0,665 & 0,665 & 0,665 \\
\hline Potássio (\%) & 0,783 & 0,783 & 0,783 & 0,783 & 0,783 \\
\hline Sódio (\%) & 0,15 & 0,15 & 0,15 & 0,15 & 0,15 \\
\hline Treonina digestível (\%) & 0,687 & 0,687 & 0,687 & 0,687 & 0,687 \\
\hline Treonina total $(\%)$ & 0,787 & 0,787 & 0,787 & 0,787 & 0,787 \\
\hline Triptofano digestível (\%) & 0,225 & 0,225 & 0,225 & 0,225 & 0,225 \\
\hline Triptofano total $(\%)$ & 0,252 & 0,252 & 0,252 & 0,252 & 0,252 \\
\hline \multicolumn{6}{|c|}{$\begin{array}{l}\text { Composição por kg do produto 1,2: 1Mistura vitamínica: Vit. A - 12.000.000UI; Vit. D3 - 3.600.000I; Vit. } \\
\text { E - 3.500UI; Vit. B1 - 2.500mg; Vit. B2 - 8.000mg; Vit. B6 - 5.000mg; ácido pantotênico - 12.000mg; } \\
\text { biotina - 200mg; Vit. K - 3.000mg; ácido fólico - 1.500mg; ácido nicotínico - 40.000mg; Vit. B 12 - } \\
\text { 22.000 mg; Se - 150mg; veículo q.s.p. - } 1.000 \mathrm{~g} \text {; 2Mistura mineral: } \mathrm{Mn}-160 \mathrm{~g} ; \mathrm{Fe}-100 \mathrm{~g} \text {; Zn - 100g; Cu - } \\
\text { 20g; Co - 2g; I - 2g; veículo q.s.p. - 1.000g. } \\
\text { 3PCSc - parede celular de Saccharomyces cerevisiae. }\end{array}$} \\
\hline
\end{tabular}


As aves foram criadas em um galpão fechado de alvenaria com dimensões $11 \mathrm{~m} \times 6 \mathrm{~m}$, coberto de telhas de barro, janelas do tipo basculante e piso de cimento, e alojadas em duas fileiras de cinco baterias de aço galvanizado de cinco andares com gaiolas de $100 \mathrm{~cm}$ de frente $\times 33 \mathrm{~cm}$ de profundidade $\times 15 \mathrm{~cm}$ de altura (subdivididas em três repartições iguais de $33,33 \mathrm{~cm})$. Cada gaiola era composta de um comedouro tipo calha, bebedouro do tipo niple, coletor de ovos e bandeja para as excretas. Tanto a água quanto as rações foram fornecidas à vontade durante todo período experimental. O manejo e os equipamentos utilizados foram os convencionais para a criação de codornas japonesas, adequando-os às condições do galpão experimental.

As aves foram pesadas no primeiro dia do experimento e alojadas em baterias experimentais de forma inteiramente casualizada. O período de adaptação das aves às rações experimentais foi de sete dias e, quando completaram 49 dias de idade, iniciou-se a coleta de dados. O programa de luz utilizado possuía um fornecimento inicial de 14 horas de luz diária, e aumentos semanais de 30 minutos, até que se atingisse 17 horas de luz diária, permanecendo nessa quantidade até o término do período experimental.

As variáveis avaliadas foram, para desempenho: consumo de ração (g/ave/dia), produção de ovos (\%), peso médio dos ovos $(\mathrm{g})$, massa de ovos $(\mathrm{g})$, conversão alimentar por massa e por dúzia de ovos produzidos e viabilidade; e para qualidades dos ovos: peso dos ovos (g), percentagem dos constituintes do ovo (gema, albúmen e casca) e espessura de casca ( $\mathrm{mm})$.

Ao final de cada período era feita uma média para determinar o consumo de ração no ciclo. Para pesagem, foi utilizada balança digital com precisão de $0,01 \mathrm{~g}$ e foi considerado para cálculo do consumo (g/ave/dia) o total de ração fornecido em cada período. O total de ração consumida foi dividido pelo número de codornas e pelo número de dias avaliados. Na ocorrência de óbito, a ração do comedouro foi imediatamente pesada para o cálculo do consumo de ração corrigida.

A avaliação de postura (\%) foi realizada tendo como base a produção diária de ovos. A produção de cada tratamento/repetição para obtenção das médias de cada período foi calculada considerando-se a produção de ovos para intervalos de 21 dias. E a avaliação da massa de ovos ( $\mathrm{g}$ ) foi realizada tendo como base a produção média de ovos (unidade) no intervalo de 21 dias multiplicado pelo peso médio dos ovos para cada tratamento/repetição no período equivalente, que foi obtido após pesagem de todos os ovos coletados do dia em balança digital de precisão nos últimos três dias de cada ciclo.

O cálculo do índice de conversão alimentar por dúzia de ovos foi obtido considerando-se o consumo total de ração $(\mathrm{kg})$ no intervalo de 21 dias dividido pela soma da produção total de ovos em dúzias para cada tratamento/repetição no período equivalente e por massa de ovos produzidos foi considerado $\mathrm{o}$ consumo total de ração $(\mathrm{kg})$ dos tratamento/repetições em períodos de 21 dias, dividido pela massa de ovos $(\mathrm{kg})$ do período equivalente. A viabilidade foi obtida pela relação entre o número de aves vivas ao final e ao início do experimento, e expressa em percentagem.

As avaliações de qualidade dos ovos foram realizadas em intervalos de 21 dias no Laboratório de Análise de Produtos de Origem Animal do Instituto de Zootecnia da Universidade Federal Rural do Rio de Janeiro. Para cada avaliação, foram coletados dez ovos de cada tratamento, por três dias consecutivos, totalizando assim 150 unidades avaliadas para cada período de 
21 dias. Para todas as análises, com exceção das medidas de peso e espessura da casca, as avaliações foram realizadas no mesmo dia da coleta.

Após coleta os ovos foram identificados, pesados em balança digital com precisão de $0,01 \mathrm{~g}$, quebrados e seu conteúdo despejado sobre mesa de vidro. Para obtenção das percentagens dos componentes dos ovos, as gemas foram separadas do albúmen e pesadas em balança digital com precisão de $0,01 \mathrm{~g}$, e as cascas lavadas para retirar os resquícios de albúmen e secas em temperatura ambiente por 24 horas, para posterior obtenção do peso da casca. O peso do albúmen foi obtido subtraindo-se, do peso do ovo, o peso da gema e da casca. A espessura da casca foi aferida após secagem das amostras, utilizando-se um micrômetro analógico de pressão. Os valores de espessura foram obtidos a partir da realização de duas leituras nos fragmentos da zona equatorial da casca.
Obteve-se a espessura da casca pela média destes dois pontos.

Os resultados obtidos foram submetidos à análise de variância utilizando-se o Programa BioEstat ${ }^{\circledR}$. Posteriormente, os efeitos dos níveis de prebiótico foram estimados por meio de análise das variáveis pelos modelos de regressão linear e quadrática ao nível de significância de 5\%, conforme o melhor ajustamento obtido para cada variável, baseado no maior valor de coeficiente de determinação para a escolha do modelo.

\section{RESULTADOS E DISCUSSÃO}

Os resultados referentes ao desempenho produtivo obtido para os diferentes níveis de inclusão da parede celular de $S$. cerevisiae (PCSc) nas rações das codornas japonesas são apresentados na Tabela 2.

Tabela 2. Efeito dos níveis de parede celular de $S$. cerevisiae no desempenho produtivo de codornas japonesas na fase de produção.

\begin{tabular}{|c|c|c|c|c|c|c|c|}
\hline \multirow{2}{*}{ Variáveis } & \multicolumn{5}{|c|}{ Tratamentos } & \multirow{2}{*}{ Regressão } & \multirow{2}{*}{$\mathrm{CV} \%$} \\
\hline & Controle & PCSc 0.5 & PCSc 1 & PCSc 1.5 & PCSc 2 & & \\
\hline Consumo ração (g/ave/dia) & 27,410 & 25,668 & 24,644 & 24,629 & 24,988 & Q & 2,36 \\
\hline Produção ovos (\%) & 84,141 & 88,422 & 88,486 & 89,369 & 87,607 & Q & 3,65 \\
\hline Peso ovos (g) & 12,595 & 12,447 & 12,083 & 12,253 & 12,282 & $\mathrm{~ns}$ & 4,87 \\
\hline Massa ovos (g) & 10,665 & 11,009 & 10,908 & 10,731 & 10,905 & $\mathrm{~ns}$ & 6,13 \\
\hline Conversão alimentar/dúzia & 0,272 & 0,237 & 0,228 & 0,243 & 0,236 & $\mathrm{Q}$ & 3,59 \\
\hline Conversão alimentar/massa & 2,570 & 2,333 & 2,296 & 2,258 & 2,279 & Q & 5,05 \\
\hline Viabilidade & 98,90 & 98,921 & 99,180 & 97,132 & 99,170 & $\mathrm{~ns}$ & 4,76 \\
\hline
\end{tabular}

O consumo de ração foi reduzido quando se adicionou prebiótico até o nível de $1,41 \mathrm{~kg} / \mathrm{t}$, evidenciando um efeito quadrático $\quad\left(\mathrm{y}^{\prime}=1,2231 \mathrm{x}^{2}-3,4231 \mathrm{x}+\right.$ 26,7862; $\left.\mathrm{R}^{2}=0,89\right)$ nos valores dessa variável (Figura 1). Os mananoligossacarídeos presentes na parede celular de S. cerevisiae reduzem a presença de patógenos no intestino (MATHEW, 2001) e aumentam a produção de ácidos graxos de cadeia curta (AGCC) após sua fermentação, e esses ácidos estão associados à proliferação celular no epitélio intestinal, aumentando 
a área de absorção de nutrientes, consequentemente fazendo com que a ave necessite de um consumo de ração menor para suprir suas exigências nutricionais. (OLIVEIRA et al., 2008).

Semelhante ao observado na presente pesquisa, Oliveira et al. (2009) observaram diminuição no consumo de codornas japonesas após inclusão de 0,1\% de MOS na ração. Ibrahim (2011), trabalhando com codornas japonesas, também obteve diminuição no consumo após inclusão de MOS + $\beta$-glucano nos níveis, variando de 0,5 a $2,0 \mathrm{ml} / \mathrm{L}$ rações.

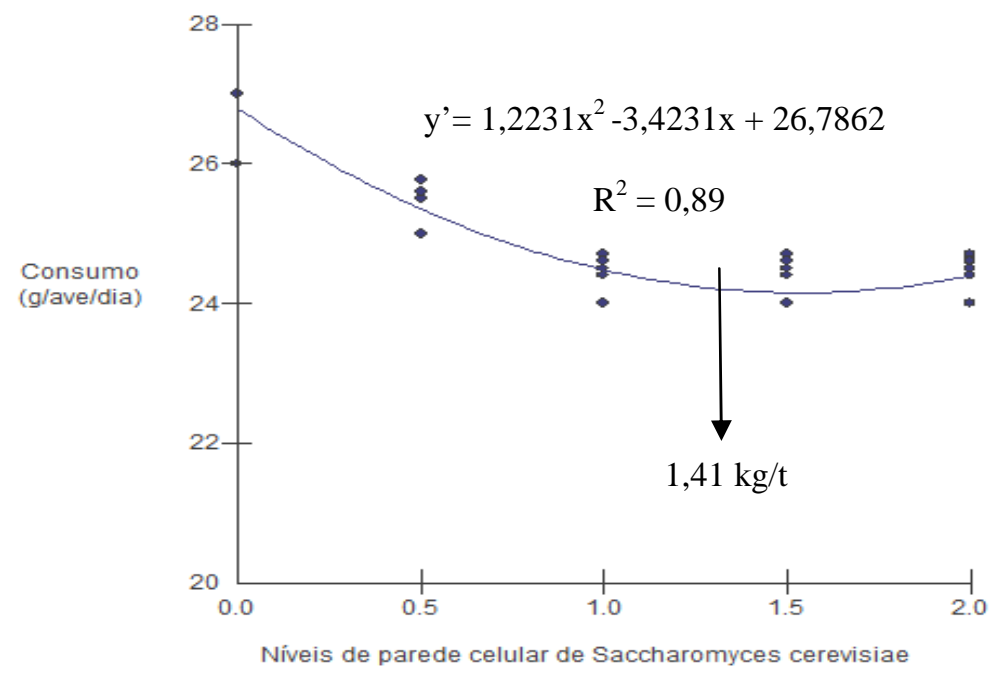

Figura 1. Consumo de ração em função dos níveis de parede celular de S. cerevisiae

O mesmo efeito foi observado em galinhas poedeiras alimentadas com dietas com inclusão do MOS, associado ou não com ácidos orgânicos por Ribeiro et al. (2010). Já Ghosh et al. (2007) não observaram diferenças significativas no consumo de ração após a inclusão de $1 \mathrm{~g} / \mathrm{kg}$ de MOS nas dietas de codornas japonesas e Ayanwale et al. (2006), Hosseini et al. (2006), Yousefi \& Karkoodi (2007) pesquisando o fornecimento de MOS para galinhas poedeiras em níveis variando de $0,25 \mathrm{~kg} / \mathrm{t}$ a $1,50 \mathrm{~kg} / \mathrm{t}$ também não encontraram diferenças significativas no consumo de ração. Em contrapartida, Oguz \& Parlat (2004), Costa et al. (2008) e Bonos et al. (2010) observaram aumento no consumo de ração em codornas japonesas que receberam ração com $1 \mathrm{~g} / \mathrm{kg}$ de MOS,
0,05\% de Bio-Mos, 2g/kg de MOS na ração, respectivamente.

Os valores médios de produção de ovos revelaram efeito quadrático $\left(\mathrm{y}^{\prime}=1,7834 \mathrm{x}^{2}\right.$ - 5,32x+ 84,8995; $\left.\quad \mathrm{R}^{2}=0,873\right)$ evidenciando um aumento na porcentagem de postura quando se adicionou prebiótico até o nível de $1,49 \mathrm{~kg} / \mathrm{t}$. A partir da adição de níveis mais altos, ocorreu um decréscimo na produção de ovos (figura 2). As codornas japonesas apresentam uma taxa de passagem da digesta bem rápida quando comparada com frangos de corte $\mathrm{e}$ galinhas poedeiras e a presença de alta quantidade de oligossacarídeos na dieta (níveis acima de $1,5 \mathrm{~kg} / \mathrm{t}$ ) pode estimular ainda mais o trânsito intestinal, diminuindo assim a digestibilidade dos nutrientes, consequentemente diminuindo a produção de ovos. (COSTA et al., 2008) 


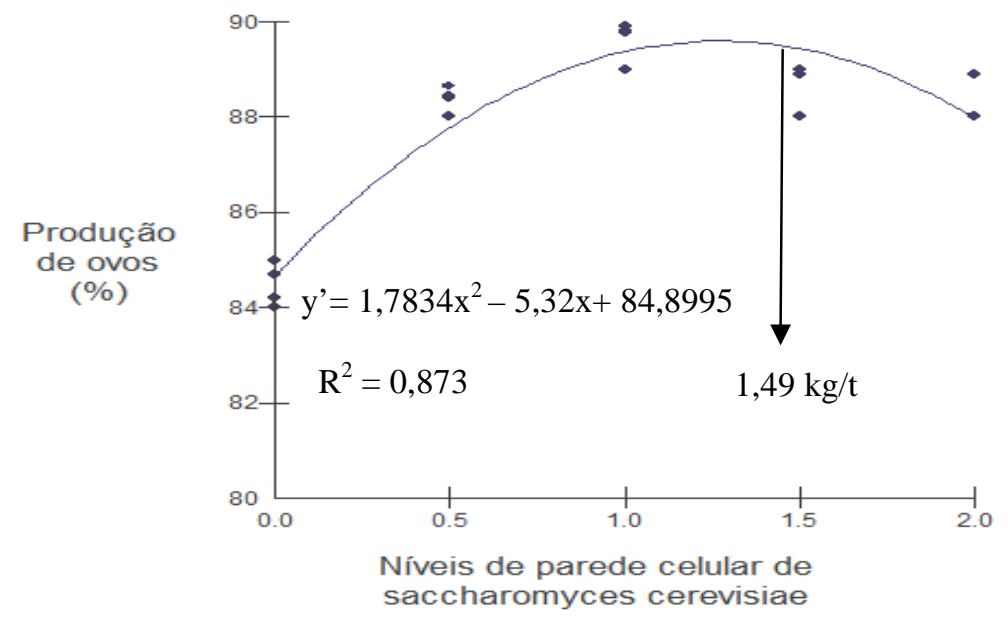

Figura 2. Produção de ovos em função dos níveis de parede celular de $S$. cerevisiae

Resultados semelhantes aos encontrados na presente pesquisa foram observados por Dimovelis et al. (2003), que observaram aumento significativo $(\mathrm{P}<0,05)$ na produção de ovos após adição de MOS $(1,00 \mathrm{~kg}$ e $1,50 \mathrm{~kg} / \mathrm{t})$, em dietas de galinhas poedeiras Lohman Brown; Garcia et al. (2004) também observaram aumento na produção de ovos em relação ao controle sem prebióticos com a inclusão de MOS $(1,0 \mathrm{~kg} / \mathrm{t})$, na dieta de poedeiras Isa Brown e o mesmo efeito foi observado por Costa et al. (2008), após inclusão de Bio-Mos ${ }^{\circledR}$ nas dietas de codornas japonesas. Por outro lado, Zaghini et al. (2005), Hosseini et al. (2006), Yousefi \& Karkoodi (2007) e Ribeiro et al. (2010) não observaram efeito $(\mathrm{P}>0,05)$ da adição de MOS na produção de galinhas poedeiras.

A viabilidade, o peso médio e a massa de ovos não foram afetados $(\mathrm{P}>0,05)$ pela inclusão de PCSc na dieta (tabela 2). Resultados semelhantes foram encontrados por Costa et al. (2008) quando pesquisaram a inclusão de prebiótico na ração de codornas japonesas e também por Oliveira et al. (2009), que incluíram $0,1 \%$ de MOS às dietas dessas aves. No entanto,
Ayanwale et al. (2006) observaram aumento no peso dos ovos após adição de prebiótico à base de $S$. cerevisiae $(0,75 \mathrm{~kg} / \mathrm{t})$ na dieta de poedeiras.

Tanto na conversão alimentar por massa de ovos quanto por dúzia de ovos, observou-se efeito quadrático $\left(y^{\prime}=0,160 x^{2}-0,4640 x+2,5540\right.$ e $\left.y^{\prime}=0,0229 x^{2}-0,0572 x+0,2648\right)$, onde se pode constatar uma melhora na conversão alimentar quando se adicionou prebiótico até o nível de $1,45 \mathrm{~kg} / \mathrm{t}$ e $1,25 \mathrm{~kg} / \mathrm{t}$, respectivamente (Figuras 3 e 4). Os prebióticos estimulam o crescimento e a atividade de bactérias benéficas, que atuam positivamente no sistema imune $\mathrm{e}$ promovem melhorias no ambiente e no epitélio intestinal (LIMA, 2008), melhorando assim a capacidade digestiva e absortiva intestinal, possibilitando-se desta forma um melhor aproveitamento dos nutrientes e um melhor desempenho das aves. Resultados semelhantes aos do presente estudo foram encontrados por Bozkurt \& Baser (2002), que notaram melhora na média de conversão alimentar $(\mathrm{kg} / \mathrm{kg})$ de galinhas poedeiras com inclusão de $\operatorname{MOS}(1,0 \mathrm{~kg} / \mathrm{t})$ nas dietas, por Ghosh et al. (2007) e por Oliveira et 
al. (2009), que, trabalhando com codornas japonesas, observaram melhora na conversão alimentar $(\mathrm{kg} / \mathrm{dz})$ após inclusão de MOS na ração quando comparado com o tratamento controle. Porém, Oguz \& Parlat (2004), Costa et al. (2008) e Bonos et al. (2010) não verificaram influência na conversão alimentar com a inclusão de prebiótico na ração de codornas.

Como observado para produção de ovos (Figura 2), a inclusão de níveis mais altos de prebiótico nas dietas das codornas japonesas provocou uma piora na conversão alimentar tanto por dúzia quanto por massa de ovos (Figuras $3 \mathrm{e}$ 4). O prebiótico utilizado nesta pesquisa foi a parede celular de $S$. cerevisiae, que é um oligossacarídeo a base de alfamanose e beta-glucose. (KOGAN \& KOCHER, 2007) De acordo com Costa et al. (2008), a presença de alta quantidade de oligossacarídeo na dieta de codornas japonesas pode acelerar ainda mais o trânsito intestinal, levando a uma diminuição na digestibilidade dos nutrientes, consequentemente piorando a conversão alimentar.

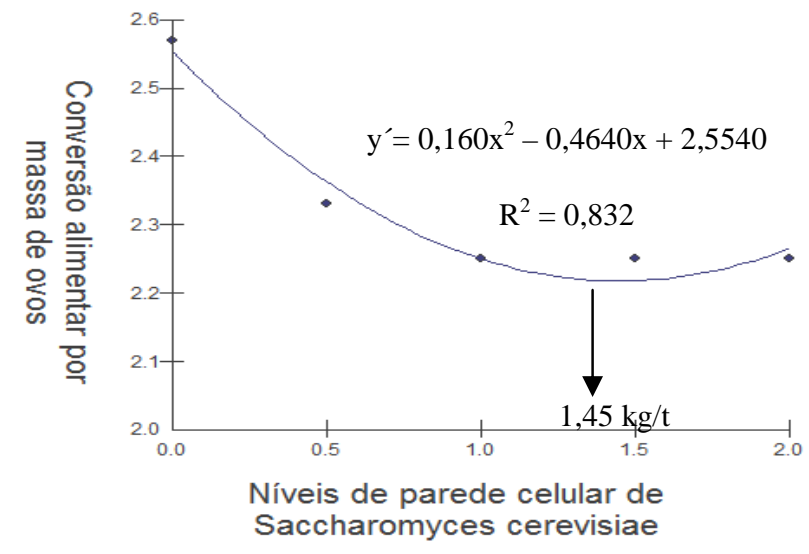

Figura 3. Conversão alimentar por massa de ovos em função dos níveis de parede celular de $S$. cerevisiae

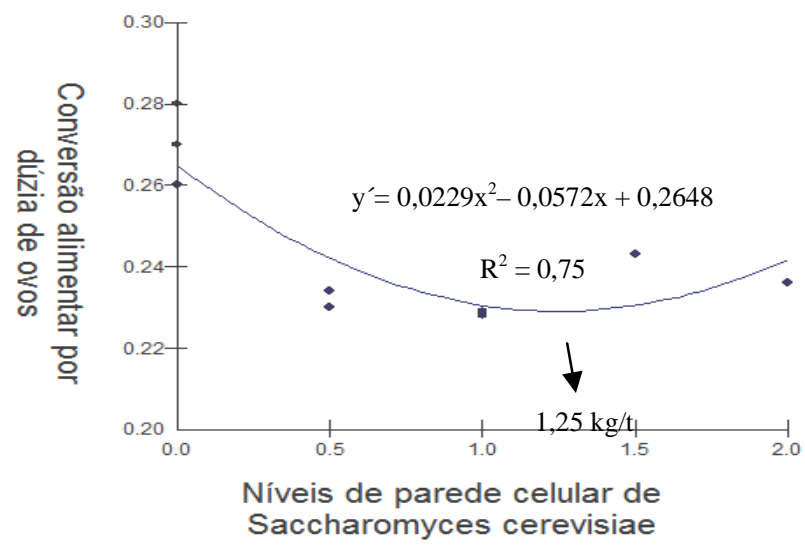

Figura 4. Conversão alimentar por dúzia de ovos em função dos níveis de parede celular de $S$. cerevisiae. 
Rev. Bras. Saúde Prod. Anim., Salvador, v.15, n.3, p.613-625 jul./set., 2014 http://www.rbspa.ufba.br ISSN 15199940

Os resultados referentes à qualidade dos ovos produzidos pelas codornas japonesas obtidos para os diferentes níveis de inclusão da parede celular de S. cerevisiae (PCSc) estão apresentados na Tabela 3 .

Tabela 3. Qualidade dos ovos produzidos por codornas japonesas na fase de produção, alimentadas com rações contendo diferentes níveis de parede celular de $S$. cerevisiae

\begin{tabular}{lccccc}
\hline Tratamentos & $\begin{array}{c}\text { Peso do Ovo } \\
(\mathrm{g})\end{array}$ & \% gema & \% albúmen & \% casca & $\begin{array}{c}\text { Espessura casca } \\
(\mathrm{mm})\end{array}$ \\
\hline Controle & 12,595 & 29,539 & 61,770 & 8,69 & 0,214 \\
PCSc0,5 & 12,447 & 30,661 & 61,018 & 8,33 & 0,220 \\
PCSc1 & 12,083 & 30,743 & 60,170 & 9,091 & 0,227 \\
PCSc1,5 & 12,253 & 30,719 & 59,534 & 9,470 & 0,228 \\
PCSc2 & 12,582 & 30,553 & 60,503 & 9,231 & 0,227 \\
Regressão & $\mathrm{ns}$ & $\mathrm{ns}$ & $\mathrm{ns}$ & $\mathrm{L}$ & $\mathrm{Q}$ \\
CV \% & 4,65 & 3,98 & 6,74 & 5,91 & 3,84 \\
\hline Q = efeito quadrático (P<0,05); L - efeito linear $(\mathrm{P}<0,05) ;$ ns - não significativo para análise de regressão (P>0,05); PCSc $=$ Parede \\
Celular de Saccharomyces cerevisiae. \\
CV = coeficiente de variação.
\end{tabular}

O peso dos ovos, percentagem de gema e percentagem de albúmen não foram influenciados pela inclusão de PCSc na ração das codornas $(\mathrm{P}>0,05)$. Semelhante ao encontrado no presente estudo, Costa et al. (2008), após testarem os níveis $0,05 \%$ e $0,1 \%$ de Bio-Mos e Bioplex para codornas japonesas, também não observaram diferenças significativas para percentagem de albúmen entre $\mathrm{o}$ tratamento controle negativo e tratamento com prebiótico. A inclusão de $0,1 \%$ de MOS na dieta também não influenciou as percentagens de gema e albúmen e o peso dos ovos produzidos por codornas japonesas no estudo realizado por Oliveira et al. (2009).

Em relação à qualidade externa dos ovos foi observada melhora na espessura da casca e aumento na percentagem da casca em relação ao peso do ovo após a inclusão de parede celular de $S$. cerevisiae nas dietas das codornas japonesas.

Conforme os resultados da análise de regressão apresentados na figura 5, observou-se comportamento expresso por uma função linear $\left(\mathrm{y}^{\prime}=0,3664 \mathrm{x}+\right.$ 8,6740), mostrando que, à medida em que houve acréscimo de PCSc na dieta das codornas, a percentagem de casca dos ovos foi aumentando linearmente $(\mathrm{P}<0,05)$.

Quanto à análise de regressão para os valores de espessura de casca observou-se efeito quadrático $\left(y^{\prime}=-0,0051 x^{2}+0,0169 x+0,2144\right.$; $\left.\mathrm{R}^{2}=0,97\right)$, onde se pode constatar um aumento da espessura quando se adicionou prebiótico até o nível de 1,5kg/t (Figura 6).

De acordo com Ferket (2004) o uso de prebiótico provoca melhora na integridade da mucosa intestinal, o que pode contribuir para uma maior absorção de nutrientes. Especialmente o cálcio, pois de acordo com Kruger et al. (2003) e Zafar et al. (2004), quando o MOS alcança o intestino grosso, ele é fermentado pela microflora intestinal e convertido em ácido graxo de cadeia curta (AGCC), que diminuem o $\mathrm{pH}$ luminal, solubilizando o cálcio e favorecendo a sua absorção. Os AGCC também causam hipertrofia das células da mucosa intestinal, aumentando a superfície de absorção. Suzuki \& Hara (2004) relataram que os oligossacarídeos podem, igualmente, 
Rev. Bras. Saúde Prod. Anim., Salvador, v.15, n.3, p.613-625 jul./set., 2014 http://www.rbspa.ufba.br ISSN 15199940

aumentar a absorção de cálcio no intestino delgado pela via paracelular, por meio de estímulo direto sobre o epitélio do intestino delgado, consequentemente melhorando a qualidade externa dos ovos.

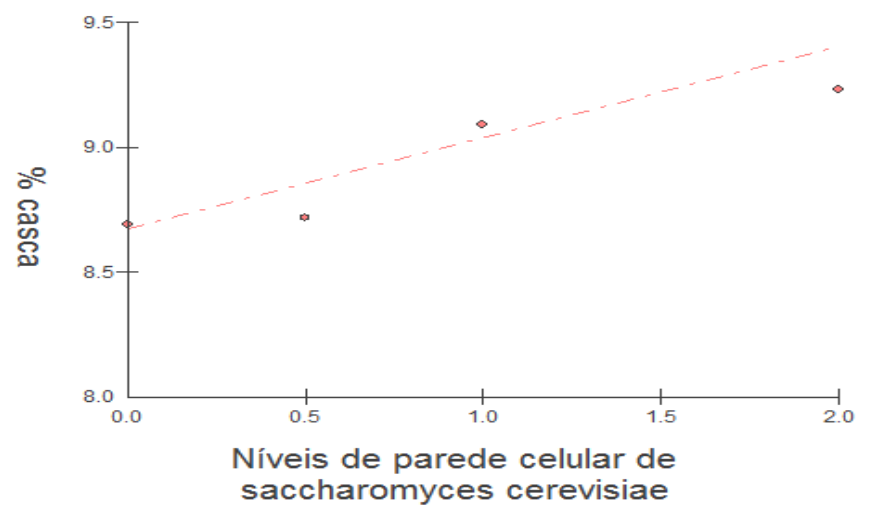

Figura 5. Percentagem de casca dos ovos de codornas japonesas em função dos níveis de parede celular de $S$. cerevisiae

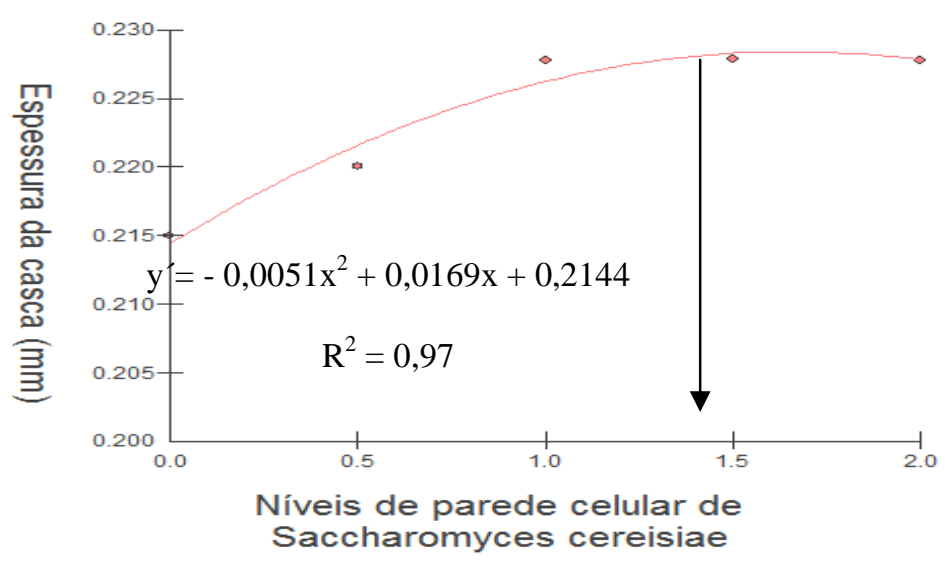

Figura 6. Espessura de casca dos ovos de codornas japonesas em função dos níveis de parede celular de Saccharomyces cerevisiae

Resultados semelhantes aos do presente estudo foram encontrados por Ayanwale et al. (2006), que observaram melhora na qualidade da casca de ovos produzidos por galinhas poedeiras com inclusão de $0,75 \mathrm{~kg} / \mathrm{t}$ de prebiótico à base de $S$. cerevisiae. Yousefi \& Karkoodi (2007) também observaram melhora no peso da casca em ovos produzidos por poedeiras Hy-Line após adição de $\operatorname{MOS}(1,0 \mathrm{~kg} / \mathrm{t}$ e $1,5 \mathrm{~kg} / \mathrm{t})$ e Oliveira et al. (2009), ao trabalharem com codornas japonesas, observaram melhora na espessura da casca $(\mathrm{P}<0,05)$ após inclusão de $0,1 \%$ de MOS às dietas. No entanto, Costa et al. (2008) não observaram efeito significativo $(\mathrm{P}>0,05)$ da inclusão de Bio-Mos na 
Rev. Bras. Saúde Prod. Anim., Salvador, v.15, n.3, p.613-625 jul./set., 2014 http://www.rbspa.ufba.br ISSN 15199940

dieta de codornas japonesas nos parâmetros de qualidade da casca. Ribeiro et al. (2010) também não observaram efeito significativo na percentagem de casca após a inclusão de $0,05 \%$ de MOS à dieta de poedeiras Isa Brown.

Conforme os resultados obtidos, concluiu-se que a inclusão de níveis crescentes de parede celular de $S$. cerevisiae, até o nível de $1,5 \mathrm{~kg} / \mathrm{t}$ na dieta, melhorou a produção, a conversão alimentar por dúzia e por massa e a qualidade da casca de ovos produzidos por codornas japonesas.

\section{AGRADECIMENTOS}

À Coordenação de Aperfeiçoamento de Pessoal de Nivel Superior (Capes), pela concessão da bolsa de estudos.

\section{REFERÊNCIAS}

AYANWALE BA, K.P.E.M; AYANWALE, V.A. The effect of Supplementing saccharomyces cerevisiae in the diets on egg laying and egg quality characteristics of pullets.

International Journal of Poultry Science, v.5, p.759-763, 2006.

BONOS, E.M.; CHRISTAKI, E.V.; FLOROU-PANERI, P.C. Performance and carcass characteristics of japonese quail as affected by sex or mannan oligosaccharides and calcium propionate. South African Journal of Animal Science, v.40, p.173-184, 2010.

BOZKURT, M.; BASER, K.H.C. The effect of antibiotic, mannan oligosaccharide and essencial oil mixture in the laying hen performance. In: EUROPEAN
SYMPOSIUM BIOACTIVE SECONDARY PLANT PRODUCTS IN VETERINARY MEDICINE, 1., 2002, Vienna, Austria. Proceedings... Vienna: [s.n.], 2002.

COSTA, F.G.P.; NOBRE, I.S.; SILVA, L.P.G.; GOULART, C.C.; FIGUEIREDO, D.F. RODRIGUES VP. The use of prebiotic and organic minerals in rations for japonese laying quail.

International Journal of Poultry

Science, v.7, p.339-343, 2008.

DIMOVELIS, P.; CHRISTAKE, E.; TSEVERINI-GOUSSI, A. et al. Effect of Bio-Mos on growth, egg production and egg quality of Lohmann brown layers. In: ALLTECH S ANNUAL NUTRITIONAL BIOTECHNOLOGY IN THE FEED AND FOOD INDUSTRIES, 19., 2003, Lexiton. Proceedings... Lexiton, Ky: [s.n.], 2003.

FERKET, P.R. Alternatives to antibiotics in poultry production:responses, practical experience and recommendations. In:

ALLTECH S ANNUAL SYMPOSIUM, 2004, Lexington. Proceedings... Lexington, USA: [s.n.], 2004. p. 54-67.

GARCIA, N.L.; CACHALDORA, P.; TUCKER, L.; BAUCELLS, F.; NEDEL, P. Effect of mannanoligossacharides suplementation to laying hen diets. Poultry Science, n. 83, p.397, 2004. Supplement 1.

GOSH, H.K.; HALDER, G.; SAMANTA, G.; PAUL, S.K.; PYNE, S.K. Effect of dietary supplementation of organic acid and mannanoligosaccharide on the performance and gut health of japonese quail (Coturnix coturnix japonica). Asian Journal of Poutry Science, v.1, p.1-7, 2007. 
Rev. Bras. Saúde Prod. Anim., Salvador, v.15, n.3, p.613-625 jul./set., 2014 http://www.rbspa.ufba.br ISSN 15199940

HOSSEINI, S.A.; LOTFOLLAHIAN, H.; KAMYABAND, A.; MADHAVI, A Study on the effect of yeast (Saccharomyces cerevisiae) utilization on the commercial layer hen's performance. Pakistan Journal of Biological Sciences, v.12, p.2346-2349, 2006.

IBRAHIM, Z.A. Modulation of immunity and some biological functions of japonese quail by mannan oligosaccharide and B-glucan administration. Egypt Poultry Science, v.31, p.867-882, 2011.

IMMERSEEL F.V.; CAUWERTS. K.; DEVRIESE, L.A.; HAESEBROUCK, F.; DUCATELLE, R. Feed additives to control salmonella in poultry. World Poultry Science Journal, v.58, p.501513, 2004.

KOGAN, G.; KOCHER, A. Role of yeast cell wall polysaccharides in pig nutrition and health protection.

Livestock Science, v.109, p.161-165, 2007.

KRUGER, M.C.; BROWN KE; COLLETT, G,; LAYTON, L.; SCHOLLUM, L.M. The effect of fructooligosaccharides with various degrees of polymerization on calcium bioavailability in the growing rat. Experimental Biology and Medicine, v.228, p.683-688, 2003.

LIMA, H.J.D.A. Prebiótico na dieta de frangos de corte. Revista eletrônica Nutritime, v.5, p.599-606, 2008.

MATHEW, A. G. Nutritional influences on gut microbiology and enteric diseases. In: ALLTECH'S ANNUAL SYMPOSIUM, 2001, Lexington, USA. Proceedings... Lexington: [s.n.], 2001. p. 49-64.
OGUZ, H.; PARLAT, S.S. Effects of dietary mannanoligosaccharide on performance of Japonese quail affected by aflatoxicosis. South African Journal of Animal Science, v.34, p.144-148, 2004.

OLIVEIRA, M.C.; MACHADO, M.G.; GONÇALVES, B.N.; MACEDO, C.M.R.; PAULA, A.P.de; ASSIS, F.A. Qualidade de ovos de codornas alimentadas com dietas que contém mananoligossacarídeos e níveis reduzidos de cálcio. Acta Scientiarum. Animal Sciences, v.30, p.277-281, 2008.

OLIVEIRA, M.C.; MACHADO, M.G.; GONÇALVES, B.N.; MACEDO, C.M.R.; ASSIS, F.A. Dietas com mananoligossacarídeo e níveis reduzidos de cálcio para codornas japonesas. Revista Brasileira de Zootecnia, v.38, n.11, p. 2193-2197, 2009.

OTUTUMI, L.K.; FURLAN, A.C.; NATALI, M.R.M.; MARTINS, E.N.M.; LODDI, M.M.; OLIVEIRA, A.F.G. Utilização de probiótico em rações com diferentes níveis de proteína sobre o comprimento e a morfometria do intestino delgado de codornas de corte. Acta Scientiarum. Animal Sciences, v.30, n.3, p.283-289, 2008.

PASTORE, S.M.; OLIVEIRA, W.P.; MUNIZ, J.C.L. Panorama da coturnicultura no Brasil. Revista eletrônica Nutritime, v.9, n.6, p.20412049, 2012.

RIBEIRO, C.L.G.; RUTZ, F.; DALLMANN, P.R.; ZAUK, N.F.; SILVEIRA, M.H.D.; GONÇALVES, R.A.S.; ANCIUTI, M.A.; ROSSI, P. Efeito da utilização de mananoligossacarídeos (MOS) e de ácidos orgânicos associados à MOS, 
Rev. Bras. Saúde Prod. Anim., Salvador, v.15, n.3, p.613-625 jul./set., 2014 http://www.rbspa.ufba.br ISSN 15199940

com e sem antibióticos, na dieta de poedeiras produtoras de ovos avermelhados. Ciência Animal

Brasileira, v.11, p.292-300, 2010.

ROSTAGNO, H.S.; ALBINO, L.F.T.; DONZELE, J.L.; GOMES, P.C.; OLIVEIRA, R.F.; LOPES, D.C.; FERREIRA, A.S.; BARRETO, S.L.T.; EUCLIDES, R.F. Tabelas brasileiras para aves e suínos: composição de alimentos e exigências nutricionais. Viçosa: Universidade Federal de Viçosa, 2011. 252 p.

SILVA, L.P.; NORBERG, J.L. Prebióticos na nutrição de não ruminantes. Ciência Rural, v.33, p.983-990, 2003.

SIMS, M.D.; DAWSON, K.A.; NEWMAN, K.E.; SPRING, P.; HOOGELL, D.M. Effects of dietary mannan oligosaccharide, bacitracin methylene disalicylate, or both on the live performance and intestinal microbiology of turkeys. Poultry Science, v. 83, p.1148-1154, 2004.

SUZUKI T.; HARA, H. Various nondigestible saccharides increase intracellular calcium ion concentration in rat small-intestinal enterocytes.

British Journal Nutrition, v.92, p.751755, 2004.
YOUSEFI, M.; KARKOODI, K. Effect of probiotic ThepaxR and Saccharomyces cerevisiae supplementation on performance and egg quality of laying hens. International Journal of Poultry Science, v.6, p.5254, 2007.

ZAFAR, T.A.; WEAVER, C.M.; ZHAO, Y.; MARTIN, B.R.; WASTNEY, M.E. Non digestible oligosaccharides increase calcium absorption and suppress bone resorption in ovariectomized rats. Journal of Nutrition, v.134, p.399402, 2004.

ZAGHINI A.; MARTELLI, G.; RONCADA, P.; SIMIOLI, M.; RIZZI, L. Mannanoligosaccharides and Aflatoxin B1 in feed forlaying hens: effects on egg quality, Aflatoxins B1 and $\mathrm{M} 1$ residues in eggs, and Aflatoxin B1 levels in liver. Poultry Science, v.84, p.825-832, 2005.

Data de recebimento: $12 / 10 / 2013$

Data de aprovação: 07/08/2014 